\title{
From a Post-traumatic Culture toward the Cultural Trauma of Post-9/11
}

\author{
Roya Jabarouti (Corresponding author) \\ Faculty of Modern Languages and Communication, University Putra Malaysia \\ E-mail: roya.jabarouti@gmail.com \\ ManiMangai Mani \\ Faculty of Modern Languages and Communication, University Putra Malaysia
}

\author{
Doi:10.7575/aiac.alls.v.5n.1p.157 \\ URL: http://dx.doi.org/10.7575/aiac.alls.v.5n.1p.157
}

Received: 04/01/2014

Accepted: 26/02/2014

\begin{abstract}
Over the past decade, the impact of the terroristic attacks of September 11, 2001 on American culture has been the prominent subject of various discussions. This has led to a large body of theoretical and experimental works known as 'post-9/11', which provides evidence for what Smelser's believes to be the cultural trauma of 9/11. This study sets out to present a review of post $9 / 11$ literature, with the perspective of cultural trauma as suggested by Neil J. Smelser, to provide a comprehensive understanding of this collective experience. This analysis highlights the role of the historical background and socio-cultural context in the establishment of cultural trauma. It also indicates the social agents and cultural elements that contributed to the embeddedness and spread of this phenomenon among the Americans. Finally, it indicates the most prominent collective response of the Americans, and as its consequences.
\end{abstract}

Keywords: Post-traumatic Culture, Cultural Trauma, post-9/11, collective coping, collective memory and collective identity

\section{Introduction}

No event has ever been so widely broadcasted as the terroristic attacks on the World Trade Center of New York, on September 11, 2001. When at 8:46, the plane entered the North tower, no one believed that it had been just the beginning of a new era in the American cultural history. However, in only seventeen minutes, when the second crash occurred, not only Americans but also the population of the whole world realized they were at the beginning of post9/11 epoch. With no hesitant, at 1:00 pm, President Bush officially declared it: "Make no mistake, the U.S. government will hunt down and punish those responsible. [...] We will show the world that we will pass this test" (Base, 2001, p. 235). Trauma for majority of the people came later, when they watched the news. The attacks were soon translated into words and numbers, and announced as the cause for landing 3,949 American airplanes, and the reason for the heaviest traffic jam within the memory of America (Huser, 2004, p. 3). Americans heard over and over that 2983 people were killed in less than two hours in America: 19 hijackers, 246 passengers, 2603 people on the ground or in the attacked buildings, and about 20 missing. Yet, the widespread trauma did not only threaten Americans, over ninety countries around the world had their citizen among the casualties, and Muslims were alienated ever after. After that day, traffic jam could cause anxiety and getting on the plane could bring shame. TV images, movies, books, paintings and talks changed their topic; a new culture arose after $9 / 11$ and continued to spread until today.

While the casualties are not comparable to those of Holocaust and Hiroshima, 9/11 attacks remained among the most documented and broadcasted events in the history and became the experience that continued to traumatize individuals and collectivities at both psychological and cultural level. Post-9/11 literature provides evidence for what Smelser's believes to be the cultural trauma of $9 / 11$. This study, offers a review on the literature written since the rise of the event by socio-cultural scholars. This review uses the theoretical perspective of Smelser's cultural trauma theory to presents a comprehensive understanding of the studies over this collective experience. This analysis highlights the role of the historical background and the socio-cultural context in the establishment of cultural trauma. It also indicates the interference of the social agents and cultural carriers in the prolonged, contested process of establishing this trauma, as well as in embedding and spreading it Americans. Finally, it indicates the most prominent collective response of the Americans, and as its immediate consequences

\section{From Trauma to Trauma Theory}

Although in the Greek roots, the term 'trauma' refers to a physical injury, it was soon applied to describe a mental damage. Trauma, as concept, became clinically well-known with the invention of railway in the late eighteenth century and the examination of the passengers who were involved in a railway accident (Caruth, 1995, p. 3). Yet, as a theory, it initiates from the clinical studies of Sigmund Freud and Breuer in their exploration of the relationship between trauma 
and hysteria, during the decade between 1888 and 1898 (Smelser, 2004, p. 32). It is this focus that Smelser much appreciates for its contribution to the understanding of the process of cultural trauma and the establishment of cultural trauma theory $(2004$, p. 32). The clinical studies of trauma gained and regained significance in the psychological examinations of the soldiers returning from World Wars, until it was officially known as Post-Traumatic Stress Disorder. The term PTSD interred the 1980 edition of the Psychiatric Association's Diagnostic and Statistical Manual of Mental Disorder, in the United States (Caruth, 1995, p. 3). Cathy Caruth, one of the major theorist of Psychological Trauma after Freud, and the one who pioneered in its conceptualization, describes this landmark as "a renew interest in the problem of trauma" (1995, p. 3).

Caruth added the elements of deconstruction into her theories of psychoanalytic trauma in the case of Holocaust. She describes psychological trauma as an overwhelming, shocking experience, to which an individual responses uncontrollably and with notable delay (Caruth, 1996, p. 11). With regards to Holocaust, LaCapra, distinguished between "acting out" and "working through" as the stages of recovery from the psychological trauma (LaCapra, 2001, p. 21). Nevertheless, within a few years, the concept of trauma become a major concern in the domain of historical, Marxist, and linguistic studies through the philosophical approaches of such scholars as Benjamin, Adorno, Derrida and their contemporaries. Clear from the subtleties of the above approaches, the theory of trauma shrinks back to a therapeutic strategy, which is currently employed clinically. When the term and the theory of trauma interred the cultural context, it added to previous load of ambiguities over the source and the process of trauma development. Doubts over the possibility of any relationship between psychological and cultural trauma triggered such questions as: Is cultural trauma the same as collective form of psychological trauma? When we speak of cultural trauma, should we really expect catastrophic event to be actually experienced? Can the cultural trauma be worked out once and forever? These questions and many other uncertainties over the status, procedure and cure of cultural trauma demanded an independent effort toward a development of cultural trauma theory by the scholars. This new academic interest, contributed to the current raise in the studies related to the development of trauma among the mass culture of American society, until the attacks of 9/11/2001 paved way for a new domain and perspective of trauma studies.

Smelser proclaims that a collective trauma is established within a prolonged, contested process in a socio-culture that is historically and structurally vulnerable and prepared for the establishment of cultural trauma. When established, it exerts claims on the membership and the collective identity of the members (2004, p.43). Neal adds that a cultural trauma occurs when the assumptions of the community about the continuity of their collective life have been shaken (2004, p. 4). Based on Smelser's definition of cultural trauma, the society must be historically and culturally trauma prone, before and at the time the traumatically potential event occurs. Moreover, the memory of the event needs to be established as culturally traumatic among the public. It means that, it should associate the collective experience with a negative affect and be regarded as an indelible scar or a threat to the society's fundamental cultural values (2004, p. 44).

It can be concluded that, a cultural trauma can disrupt the identity as it can strengthen it. This explains why in literature of social-cultural trauma, the three concepts of collective trauma, collective memory and collective identity are always presented in relation with one another. After all, cultural trauma can be officially defined as:

A memory accepted and publically given credence by a relevant membership group and evoking an event or situation which is a) laden with negative affect b) represented as indelible, and c) regarded as threatening a society's existence or violating one or more of its fundamental cultural presuppositions. (Smelser, 2004, p. 44)

\section{Post-traumatic Cultural Heritage}

Smelser makes a radical shift in proposing a definition for the cultural trauma by saying that: "No discrete historical event or situation automatically or necessarily qualifies in itself as cultural trauma, and the range of the events or situations that may become cultural trauma is enormous" (Smelser, 2004, p. 35). The distinction of this proposition is in its emphasis on the fact that although some historically catastrophic experiences have registered themselves as traumatic in the public perception, they were not automatically traumatic by nature. Sztompka in his study on the impact of the rapid changes of society on the creation of cultural trauma provides an endless list of potentially traumatic events (Sztompka, 2004, p. 156). All the same, Smelser asserts that not all of them necessarily lead to historically established cultural traumas, and still a lot more items can be added to this list (Smelser, 2004, p. 35).

Hence, the context of a society should be historically and structurally prepared, or "Trauma prone" (Smelsr, 2004, p. 36) in order be able to establish a cultural trauma. In the complex contemporary American life, trauma is likely to appear as both a psychological and cultural syndrome. From a historical perspective, the long existence of a "posttraumatic mood" (Farrell, 1998, p. 2) makes the commonest sense in America, after experiencing the worldwide catastrophes of the century. The direct experience of the Great Depression, the leading role of America in World War II, followed by the promises of tranquility that were invaded by the inauguration of the Cold War, and many other unresolved wars led by the American government around the globe, directly affected the society of America. A second formidable list could also be initiated with the assassination of the President Kennedy. This includes such human catastrophes as Bombing of Hiroshima and Nagasaki, as well as comparably minor experiences, such as riots, scandals, financial wreckages, and crises between huge economic forces that tended to "split the society in two" (Farrell, 1998, p. 2). These splits for the younger generation are still terrifying downward experiences, and backward, to the darker memories of Vietnam. This is what Farrell designates as the American mood before September 2001, and further describes to be "belated, epiphenomenal, the outcome of cumulative stress" (1998, p. 3). The trace of all the 
catastrophes had remained like a gash in the collective memory of the American society. The pre-9/11 mood mirrors a long-term damage into the body of collective trust, and 9/11 was just another reminder: 'even we can die'.

In a very interesting introduction to his essay on the American psyche after 9-11, Walter A. Davis relates an anecdote: Gandhi offers "a way out of hell" (2003, p. 127) to a Hindu man who has killed a Muslim child, and still hears echoes of this traumatic experience. Davis also proclaims that he knows the roots of the traumatic hell into which American society has fallen since September 11 2001. He points out that neither the shattering images that framed the consciousness of America, nor the anxiety that these memories arouse were enough to establish this national trauma. The basis of this collective hell was, in fact, established back on 6/8/1945 in Hiroshima (2003, p. 127), and the Hisroshimas. The images of a plane approaching the towers, the falling bodies of men and women in the horribly dark sky, the terrified fleeing crowd, and the increasing figures of the dead and the buried alive innocents, all very much resembled what Americans once heard or watched happening to other nations. The attacks of 9/11/2001, for a few minutes, made America experience what it had been like being in Hiroshima more than fifty-five years ago. America realized the images of burning-to-ash Japanese town, burring-to-death citizens, and "walking dead" survivors in an American nightmare ever after (Davis, 2003, p. 127).

\section{Cultural Trauma of Post-9/11}

\subsection{Cultural System}

According to Smelser, a system is the necessary vulnerable context into which cultural trauma can penetrate. In psychological trauma, the private system of 'personality' is open to outside damage by internalizing it through memories. The process of cultural trauma creation also requires a system, which can be defined in relation to the social system. (2004, p. 37). Social system indicates "the organization of social relations in society; its main units are social roles and institutions, and these are normally classified along functional lines- economic institutions, legal institutions, medical institutions, educational institutions, family institutions- though the idea frequently includes systems of ranking (stratification) into social classes, racial and ethical groups, and so on" (Smelser, 2004, p. 37). Therefore, social events can be regarded as a social trauma as long as they really shake the foundations of an organized society. The Great Depression, for example, can be regarded as a social trauma since it handicapped the function of economic, political and even political institutions in many societies in 1930s.

America has a widespread reputation for multi-culturalism. It has been the home to and the dreamland of people from variety of religious and cultural background. Therefore, it is necessary to explore the context of the American society in terms of unity and coherence between its sub-cultures. It becomes even more significant, by realizing that "the victims of the ground", that is, those who were inside the attacked building, were from 60 countries, and spoke in 24 different languages (Boss et al., 2003, p. 456). As studies later unfolded, many of American Muslim citizens had already been through ambiguity and loss of identity in America. The U.S., their new homeland, had considerably confronted them with the issues of racism, discrimination, etc. Therefore, despite the general conformity to the expectations of the American culture, it is difficult to think that the members of this sub-culture had constructed tight, meaningful relationship with the rest of the society. The evidence is that after the attacks, what they all sorely yearned for was a reunion with their families in their homeland, and not those whom they called "strangers" in America. This situation became a challenge (Boss et al., 2003, p. 458) for the therapists who tried to help them (Boss et al., 2003, p. 460).

Although America had developed a world-known habit of antagonism with Muslims and Islamic traditions, before September 11 2001, American Muslims could still enjoy the advantages of their citizenship. But 9/11, as it is now called, was a zero point in the history of America for all its citizens, notably Muslims; they a realized a "dramatic loss of identity and meaning, a tear in the social fabric" (Abu-Ras et al, 2013, p. 16). The cultural ties that Muslim Americans had with their society were torn down by what followed the event, to the extent that they continued their life in America struggling with a new phenomenon as "Islamophobia" (Abu-Ras et al, 2013, p. 16).

\subsection{Laying the Language of Affect}

Culture is a system which includes "a grouping of elements -values, norms, outlooks, beliefs, ideologies, knowledge, and empirical assertions (not always verified), linked with one another to some degree as a meaning-system" (Smelser, 2004, p. 37). In a national society, for example, culture is defined in relation to national references with various levels of unity and coherence, which respectively refer to the consensus of all the sub-cultures, and the tightness of logical relations between the cultural elements. In this respect, Smelser defines cultural trauma as "an invasive and overwhelming event that is believed to undermine or overwhelm one or several essential ingredients of a culture or the culture as a whole" (p. 38). Therefore, for instance, the Protestant Reformation can be regarded as a cultural trauma since it undermined the dominancy and coherence of Catholics; the nineteenth century colonialism can also be regarded as cultural trauma, because it imposed the western cultural values on the cultural integrity of the colonized societies. The cultural situation of the migrant communities can be trauma prone in the face of cultural dominancy of the host community. However, some events are psychologically, socially and culturally intrusive enough to encourage all types of trauma, if not simultaneously, with little time span from each other. The Great Depression of the 1930, which as discussed above, shook the foundation of the social institutions, can also be considered as culturally traumatic as it threaten the integrity of capitalism.

There is no doubt that the symbolic damage that this atrocity made to the American identity was far more destructive than its social, political, economic damage. In fact, in comparison to such catastrophes as Hiroshima, Holocaust or Cambodia, the literal damage of the attacks was miniscule. What distinguishes this event is its symbolism. The planes, 
in fact, assaulted the American symbols of power, modernity and identity (Redfield, 2007, p. 56), which magnified their destructive power. Still, the responses and the mechanism that America chose to deal with this situation became even far symbolic and magnifying.

As discussed previously, a widespread symbolic language of affect in a society clues to the occurrence of cultural trauma. In fact, interchange of negative emotions among individuals, links between the private psychological trauma and the collective one (Smelser, 2004, p. 42). Anxiety, since Freud, has been recognized as the commonest negative response to the traumatic situations (Smelser, 2004, p. 39). Moreover, anxiety is a universal language that effectively communicates the threat among the individuals around the globe. In the visual society of America, images, whether static or animated, play a significant role in creating, spreading and maintaining affect. Image, according to Davis, is "the language of anxiety, the language psyche uses in an effort to mediate the emotional and psychological impact of events" (Davis, 2003, p. 128). It closely resembles the fragmented language of dream with its unpredictable links and sudden changes, which, through the lens of psychology arises in the agony of the psyche. Put it differently, image is the language of the subconscious and a "concrete way to embody and mediate its pain" (Davis, 2003, p. 128). On the other hand, as Heidegger proclaims, images have "a revelatory power" that is far more salient than the language of the concept (Heideggar, 1927, p. 179).

It is an undeniable fact that the attacks of September 2001 of the New York were translated, to the images that were widely broadcasted around the world. However, Davis regards "Ground Zero", as a central image that endowed and mediated a range of negative meanings to the event. "Ground Zero", which is now the name for the ruins of the World Trade Center in New York, is originally a military term. The non-capitalized term, ground zero, was coined to designate the zero point for the first Atomic Bomb. Symbolically enough, it was later used to calculate epicenter of the Atomic Bombs that targeted Hiroshima. Davis argues that the capitalized term creates an image and, in fact, opens the way into a hidden anxiety. On one hand, it capitalizes an image of wholeness and invulnerability for a nation seeking to reconstruct its identity. On the other hand, it hides a murderous past and denies the fact that this is just another ground zero (Redfield, 2007, p. 62). Deep in, it points out to the anxiety of a nation: "the fragments shored against" our "ruins" (Davis, 2003, p. 128). Overall, the image keeps haunting the American society, making it impossible for Americans to work out the trauma once and forever. Although the events of 9/11/2001 were unpredictable and overwhelming enough to shatter American society, the images and the language used immediately by many of the social agents, whom Smelser knows as the "carriers" of cultural trauma, obviously "made [the attacks] to be [tremendously] remembered" (Smelser, 2004, p. 36), not only in America, but also elsewhere in the world. In order for a historical event to be registered as a cultural trauma, several other outer elements and agencies are involved. While in the psychological trauma the "intra-psychic dynamics of defense, adaptation, coping and working through" are the engaged mechanisms, in the cultural trauma, the "social agencies and the contending groups" (Smelser, 2004, p. 39) are at work to establish and maintain it.

\subsection{Indelibility and Claims of membership}

The next and the most necessary step for the maintenance of cultural trauma, is to ensure its embeddedness and recurrence among the collectivity. In this respect, Redfield directs the attention to the names given to the event. "September 11" and the numerical form " $9 / 11$ " rose from the mass media immediately after the attacks and remained as the only names used to refer to the events, making them "endlessly and unavoidably available" worldwide. In a society no less verbal, than visual, "9/11 discourse" penetrated into everyday cultural life, reliving trauma every time they are repeated. The terms have created a blockage by turning the event to a zero point at time, and also by metasizing their symbolism. For Redfiled it is acceptable to think that a consumerist public and politicians with military tendencies would prefer to establish this scar as indelible and non-healable at the body culture of their society. In fact this nations finds it rather impossible to find any practical mechanism for actual grieving (56). The role of the carries becomes significant not only in the establishment of the cultural trauma, but also in its persistence; since, as discussed above, a historical situation is regarded as culturally traumatic only as long as it is remembered, or made to be maintain its status as such. Carries, now, have the responsibility to "continuously and actively" (Smelser, 2004, p. 38) revive and restore this status.

The names used to refer to the event, increasingly add to its traumatic affect by distancing from the reality and the truth behind it. The name September 11, without any other supplementary tag, acquires a substantial rhetorical power that contributes to its affect in various ways. "Imperatively and imperialistically", the term September 11, "presupposes and demands knowledge" of the event, from its speakers and listeners, implying that everything changed that day (Redfield, 2007, p. 58). The reduced form, $9 / 11$ contains a lot more forces in addition to its emptiness. From 1987 when Reagan called September 11 "the Emergency Telephone Number Day", until September 11 2001, the day was officially known and celebrated to "promote safety awareness". Finally after a series of changes, on September 4 2002, Bush established the name "Patriot Day" and ignored the 316 victims who were not Americans (Redfield, 2007, p. 58). The terms, has been overtly used by the American press and mass media, and has continued to provoke a patriotic sentimentalism, or what Davis calls "patriotic gore" (Davis, 2003, p. 129) and confirms otherness of the Non-Americans. Smelser believes what powered Americans in all their attempts ranging from, denial, to resistance and violence towards Muslim Americans, whom Americans regarded as "they", was an increasing sense of defending and the loyalty to America, their homeland (Smelser, 2004, p. 277). 


\subsection{Identity Disrupting/solidifying}

Davis considers an ideal implication for the events, one that mourning and the sense of guilt, for the previous atrocities of America, has returned by the term Ground Zero to awaken Americans. Then, at the Zero place and time, they would achieve self-consciousness and recognition of what it could mean to be an equal member of the world. It would be then plausible to give the victims, who were the costs of this national awakening, an appropriate memorial (2003, p. 128). In that case, as Smelser asserts, the trauma can be described as a solidifying (2004, p. 44) national experience that could strengthen the ties between subcultures, including the Muslim Americans.

However, the ideal situation did not really happen, "nor could it" (Davis, 2003, p. 128). The "carriers" or "cultural specialist" (Smelser, 2004, p. 38) had already attempt to justify the evaporation of Hiroshima and represent it as a heroic act, which was done with so much reluctant; or as the well-known phrase says, it was done as America's "least abhorrent choice" to save the life of million Americans (Davis, 2003, p. 128). That was one story, while the sadder story is that Hiroshima was burnt just because it was typical American way to bloodshed around the world. There is no need at this point to go further exploring the many underlying reasons for that cruel attack. Nonetheless, it is necessary to state that the entire "pretty story" of Hiroshima had been written anonymously for the Secretary of State of the time (Davis, 2003, p. 128), to dictate it to the whole nation as "the whole story" (Smelser, 2004, p. 55). As expected, a similar sort of whole story needed to be written about 9/11, to put down all the dispute and ambivalence among the public, which will be discussed later in the final section of coping mechanism. However, the other story of $9 / 11$, that is, what happened at the backstage, caused what Smelser calls "splitting" and distorted the integrity of American society. When cultural split reaches to extreme levels, it results in the partial or complete silence of one side and rise in the voice of another. At the social stage, it looks more like a "cultural play, or a "cultural war" lead by polarized political groups (Smelser, 2004, pp. 54-5). After September 11 2001, the innocent victims became the excuse for scapegoating American Muslims at home, and targeting other Muslims wherever America labeled as the site of terrorism (Davis, 2003, p. 129).

\section{Coping Mechanism}

In the psychoanalytic realm, "fighting back" of the affected individuals, against the traumatic experience, has existed since the earliest findings of Freud, and has lead to the appearance of such the notions as "coping" and "defense" mechanisms or strategies against the trauma. However, according to Smelser, the literature used to define and classify the "stages" and "modes" of psychological trauma suffers from loads of confusion, vagueness, repetition, generalization and overlapping. Following Freud's tradition of psychoanalysis, Smelser defines the defense mechanism against trauma as a sequence of internal reactions: accumulation of unsatisfied tension, which in turn, arouses the representations of psychic drive, related affects, fantasized satisfying objects and finally some "motor activity" that changes the state of this system and calm down the tension. At any of these stages, Smelser believes, there is the possibility for the defense mechanism to be activated. In addition to these stages in the defense process, he has also recognized four various mode of defending: blocking the interference of threat, converting the type of this interference, shifting the targets, and finally isolation of the threat. In spite of that, as the evidence show, the traumatized individual may use two or more of defense modes at the same time (2004, p. 45). Moreover, the stages and the modes of defense strategies are not limited to internal threats. That is, in the case any external threat as well, the individual may resort to suppression, denial, displacement, projection or depersonalization, and so on.

On the other hand, although the term "defense mechanism" has a broad record, Smelser prefers the term "coping mechanism" or "coming to terms with" to refer to this process. As he argues, while the former posits the individual actively in the face of the threat, the later ones remain more neutral (2004, p. 47). Adopting a broader perspective, it is evident that human beings have always been involved in various forms of internal and external threats in their lives. As a result, it is possible to regard this defense mechanism, as universally known strategies of coping, or a universal language that links collectivities and individuals around the world. For instance, everyone knows what it means to reverse love, to deny or to scapegoat. This, what Smelser calls, "shareability" (Smelser, 2004, p. 47), is a presupposition in understanding the collective coping of the cultural trauma.

\subsection{Denial, Converting, Projection, and Ambivalence}

The terms used to refer to the attacks of September 11, 2001, not only gave way to the psychological and cultural trauma that followed the attacks, but also revealed the strategy American took in search of recovery. According to Davis, the fact that the term ground-zero was capitalized was a proof for "calling upon the mechanisms of projection and denial" (2003, p. 128). By denial he meant, denial of the fact that America, for what she had already done, was responsible for being attacked and targeted now. Similarly, Redfield asserts that capitalization of the term Ground Zero, reveals an underlying attempt of denial of the fact that the site was just another targeted ground zero in the history. Put it differently, as one of their first strategies, American cultural carries resorted to a strategy that best suit the American public and politicians; that is, denial of being responsible for the past mistakes and denial of vulnerability of the American dream. In addition, by distancing the public from the reality behind this story, it blocked mourning, which in turn belated the recovery. The other terms used to refer to the event, also serves as the similar purposes (2007, p. 56).

Secondly, although the bombing of Hiroshima by America was the first terroristic act in the globe, the term groundzero, capitalized, helped convert America to a site for the innocent victim of global terrorism, and therefore, assumed American government a mission to cleanse the world from terrorists (Spivak, 2004, p. 82). Consequently, this led to the third mechanism of coping with cultural trauma, that is, scapegoating and finger pointing others, or the most hated ones. 
In fact, the terms officially allowed projection of responsibility and guilt on Muslims. As a result, scapegoating occurred at both national and international level, aiming Muslims and whoever with minimal resemblance to them in name, language, or appearance. American Muslim were, afterwards, known as "they", "the suspected perpetrators" (Abu-Ras et al, 2013, p. 16), as opposed to "we" the real victims. Davis sees this American habit of targeting and demonizing, as a projection at unlimited scope, one that finds targets anytime and anywhere it needs them (2003, p. 129). The evidence is that, soon after the attacks, the Congress passed the USA Patriotic Act, which "authorized the federal government to arrest, detain, and deport non-American citizen (Abu-Ras et al, 2013, p. 12). This so called counter-terroristic policy, rose the figure to 2,000 to 5,000 arrested Muslims and Arabs (Akram, 2004, p. 620).

Although not all Americans agreed with the antagonism towards their Muslim neighbors or colleagues, politicians and public servants, who were the primary source of the discourses released to public targeted Muslim professionals. In other words, 9/11 terminology described all Muslims as extremists, killers and terrorists. According to Abu-Ras et al. these attempts spread a sense of islomiphobia, or anti-muslim to about twenty-five to fifty percent of the population at various areas. "Islomophobic discourse portrayed Islam as monolithic and threatening, Muslims as using Islam to gain advantages for ideological goals, and Muslim culture as significantly and adversely different from other cultures" (AbuRas et al, 2013, p. 12). This was while such social and linguistic scholars as Noam Chomsky argued that $9 / 11$ was not only about religion, and the term "religion" (Spivak, 2004, p. 82) should not be attached to it immediately in seek of the responsible. Spivak defines American war on terrorism, in general, as "a cruel caricature of what in us can respond" to situations that arouse self-guilt. What makes the American War on terror distinctive is that it is a fight against an abstract enemy (2004, p. 81).

As the result of this biased game of cultures, Muslim American were traumatized as both victims and perpetrators. Although the situation could not be fully "worked out through", Muslim Americans did not remain silent either, and developed their own strategies of coping. As the studies show, on the contrary, Muslim Americans regarded the situation as a chance for the Muslim Community to expand their social understanding by sympathizing with the other affected Americans. The replacement strategy had also been taken by the Americans, but that turned out to more "problematical" and "splitting" (pp. 54-5) than healing, as it generated a second level of trauma for their fellow Muslim Americans and isolated them from the rest of the society. The point is not that Muslims did not face an initial dispute and confusion over the interpretation of the situation and the proper reaction, but that they managed to shift the negative situation to positive one to assure their own survival, while still considering welfare of the others.

\section{Conclusion}

The fact that no event of history had ever been so widely broadcasted as the terroristic attacks to the American towers on September 11 2001, reinforces the idea that no event is inherently traumatic. Moreover, a comparison between the casualties of the attacks and those of Holocaust, Hiroshima, Cambodia and the attacks of September 9/11 further strengthen the idea that trauma is not inherent in all historical catastrophes. Because cultural trauma will be established within a Any community that undergoes a potentially traumatic experience, needs to be historically and structurally prepared for its establishment The experience of the Great Depression, World War II, as well as the Cold War, and many other unresolved wars led by the America around the globe, had already affected the society of America. In other words, American memory had the scare of previous gashes on it much before the attacks took place. Moreover, America has a widespread reputation for its multi-culturalism, as well as nationalism. It had been the home to people from variety of religious and cultural background, which at the same time entangled with cultural sophistications, as a super power.

It is an undeniable that the attacks mean to symbolically bring America to its knees and to shake the foundations of its cultural straucture once again. What is more, the attacks were, by means of social agents and cultural carriers, translated, to the images and words that contributed to this symbolism. Ground Zero, as a central image endowed and mediated a range of negative meanings to the event, and to the Americans as the innocent, vulnerable targets. Deep in, it points out to the long term anxiety of a nation about the consequences of they had already done to the others. Embodied in an image, the anxiety keeps haunting the American society and makes it impossible for them to work out the trauma once and forever. The names used to refer to the event, had an increasingly affect on the traumatic affect by distancing the subjects from the reality of the event, as well as the truth behind it. September 11, or 9/11, acquire a substantial rhetorical power that contributes to its affect in various ways. While they demand the detail knowledge from the listener, they highlight the traumatic force, by distinguishing it from the other September $11 \mathrm{~s}$ on the calendar. These terms, have been overtly used by the American press and media, since the attacks, and have continued to provoke a patriotic sentimentalism.

In response, American public and politicians resorted to pointing the condemning finger at others, instead of finding the reality and the root of the problem. This American habit of targeting and demonizing, not only traumatized all Muslims, as the suspected perpetrators, but also belated the recovery process among the Americans themselves. Moreover, it further justified the terrorization of the civilians in the name of War on Terror, and made the American memory ever more prone to the establishment of another cultural trauma. 


\section{References}

Abu-Ras, W., Senzai, F., \& Larid, L. (2013). American Muslim Physicians’ Experiences Since 9/11 Cultural Trauma and the Formation of Islamic Identity. Traumatology, 19, 11-19.

Adorno, T. W. (1982). Prisms. The MIT Press.

Akram, S. M., \& Karmely, M. (2004). Immigration and constitutional consequences of post-9/11 policies Involving Arabs and Muslims in the United States: Is alienage a distinction without a difference. UC DAViS l. reV., $38,609$.

Anker, E. S. (2011). Allegories of Falling and the 9/11 Novel. American Literary History, 23(3), 463-482.

Base, B. A. F. (2001). Remarks by the President Upon Arrival at.

Benjamin, W. (1969). Theses on the Philosophy of History. New York: IIIuminations, 255.

Boss, P., Beaulieu, L., Wieling, E., Turner, W., \& LaCruz, S. (2003). Healing loss, ambiguity, and trauma: a community based intervention with families of union workers missing after the 9/11 attack in new york city. Journal of Marital and Family Therapy, 29, 455-467.

Caruth, C. (1995). Trauma: Explorations in memory. JHU Press.

Caruth, C. (2010). Unclaimed experience: Trauma, narrative and history. JHU Press.

Davis, W. A. (2003). Death's dream kingdom: The American psyche after 9-11. Journal for the Psychoanalysis of Culture and Society, 8, 127-132.

Epstein, D., Paterson, M. S., Cannon, J. W., Holt, D. F., Levy, S. V, \& Thurston, W. P. (1992). Word processing in groups. AK Peters, Ltd.

Farrell, K. (1998). Post-traumatic culture: Injury and interpretation in the nineties. JHU Press.

Heidegger, M. (1962). Being and time (J. Macquarrie \& E. Robinson, trans.). New York: Harper \& Row.

Huddy, L., Feldman, S., Taber, C., \& Lahav, G. (2005). Threat, anxiety, and support of antiterrorism policies. American Journal of Political Science, 49, 593-608.

Huser, R. (2004). Introduction: 911 and 9/11: Links to Link. Cultural Critique, 57, 3-13.

Kaplan, E. A. (2005). Trauma culture: The politics of terror and loss in media and literature. Rutgers University Press. LaCapra, D. (2001). Writing history, writing trauma. JHU Press.

Meek, A. (2012). Trauma: With or Without Theory. Cultural Studies Review, 18, 347-352.

Neal, A. G. (1998). National trauma and collective memory: Major events in the American century. ME Sharpe.

Redfield, M. (2007). Virtual trauma: The idiom of 9/11. diacritics, 37, 55-80.

Smelser, N. J. (2004a). Epilogue: September 11, 2001, as cultural trauma. Cultural trauma and collective identity, 2, 264-282.

Smelser, N. J. (2004b). Psychological trauma and cultural trauma. Cultural trauma and collective identity, 4, 31-59.

Spivak, G. C. (2004). Terror: A speech after 9-11. boundary 2, 31, 81-111.

Sztompka, P. (2004). The trauma of social change. Cultural Trauma and Collective Identity, California University Press, Berkeley, 6, 155-197.

Thompson, K. (1998). Moral panics. Psychology Press.

Versluys, K. (2009). Out of the Blue: September 11 and the Novel. Columbia University Press. 